\title{
Effects of Laser Processing Parameters on Texturized Layer Development and Surface Features of Ti6A14V Alloy Samples
}

\author{
Juan Manuel Vázquez Martínez ${ }^{1, *}$, Jorge Salguero Gómez ${ }^{1}$ (D), Moises Batista Ponce ${ }^{1}$ and \\ Francisco Javier Botana Pedemonte ${ }^{2}$ \\ 1 Department of Mechanical Engineering \& Industrial Design, Faculty of Engineering, University of Cadiz, \\ Av. Universidad de Cadiz 10, E-11519 Puerto Real-Cadiz, Spain; jorge.salguero@uca.es (J.S.G.); \\ moises.batista@uca.es (M.B.P.) \\ 2 Department of Materials Science and Metallurgic Engineering and Inorganic Chemistry, \\ Faculty of Engineering, University of Cadiz, Av. Universidad de Cadiz 10, E-11519 Puerto Real-Cadiz, Spain; \\ javier.botana@uca.es \\ * Correspondence: juanmanuel.vazquez@uca.es
}

Academic Editor: Alicia Esther Ares

Received: 30 November 2017; Accepted: 20 December 2017; Published: 22 December 2017

\begin{abstract}
Surface engineering is widely used in different areas, such as the aerospace industry or the biomechanical and medical fields. Specifically, laser surface modification techniques may obtain specific surface finishes for special applications. In texturing laser procedures, the control of processing parameters has a great influence on the geometry and characteristics of the treated area. When these processes are carried out on titanium alloys, thin oxide layers are usually developed on the irradiated surface, formed through the thermochemical combination of vaporized material with atmospheric oxygen in the air. In thermal oxidation treatments of Ti6Al4V, the highest concentration of oxides is mainly composed by rutile $\left(\mathrm{TiO}_{2}\right)$, producing surface property modifications such as hardness, among others. In this research, a thermochemical oxidation of Ti6Al4V alloy has been performed through laser texturing, using laser scanning speed $\left(V_{s}\right)$ and pulse rate $(f)$ as process control variables, and its influence on the beam absorption capacity of the modified layer have been analyzed. Combined evaluations of microgeometrical features and mechanical properties, such as hardness, verified that, by means of laser texturing treatments, the ability to generate specific topographies and increase the initial hardness of the alloy is obtained. The most advantageous results for the increase of hardness by thermochemical oxidation have been detected in low scan speeds of laser beam treatments, resulting in an increase of approximately $270 \%$ using a scanning speed of $10 \mathrm{~mm} / \mathrm{s}$. On the other hand, a dependence between roughness values, in terms of $R_{\mathrm{a}}$ and $R_{\mathrm{z}}$, and the energy density of pulse $\left(E_{\mathrm{d}}\right)$ has been observed, showing higher values of roughness for a $17.68 \mathrm{~J} / \mathrm{cm}^{2}$ energy density of pulse.
\end{abstract}

Keywords: surface engineering; laser texturing; thermal oxidation; Ti6Al4V; surface characterization

\section{Introduction}

Titanium alloys are one of the most commonly used materials in strategic fields such as the aerospace and biomechanical industry. This fact is mainly due to the ratio between physicochemical properties and weight, and an excellent biocompatibility with organic environments [1-3]. Also, current advances in biotechnology and biomechanics induce the development of new materials and surface treatments that aim to increase wear and corrosion strength, or improve features, which allows the promotion of the biointegration of materials [4-8]. Laser processing techniques imply the ability to 
perform changes on surface material without direct contact [9-13]. This feature results in a relatively clean and precise process, due to an excellent control over the heat absorption on the affected area, and the possibility of focusing the laser beam on small areas of the surface. The exposure of Ti6Al4V alloy to radiation treatments by laser techniques in an air atmosphere causes the combination of the external surface layer with the oxygen present in ambient air, promoted by the temperature increase generated in the radiation process [14-17]. Such a combination results in the development of a thin protective layer, mainly composed of titanium oxides, with rutile $\left(\mathrm{TiO}_{2}\right)$ being the predominant form [15-17]. A range of several tonalities is shown according to variables such as the thickness and microstructure of the oxidation layer [15-17]. With the aim of ensuring the quality of results, metrological procedures are required to evaluate the dimensions of the grooves created by surface laser texturing [18].

Through variations of conditions of laser treatment, several features, such as the surface finish or the hardness, can be tuned for very specific material uses [19-21]. Based on laser surface treatments, a large number of studies are focused on improving the tribological properties of titanium alloys, induced by limitations and poor material behavior in friction sliding conditions [22,23].

In the present work, laser texturing has been performed on Ti6Al4V alloy surfaces, combining energy density on pulse $\left(E_{\mathrm{d}}\right)$ and speed scans of beam $\left(V_{\mathrm{s}}\right)$ values. In this way, the influence of intrinsic parameters of the laser processing setup on morphology, characteristics and properties of treated surfaces has been analyzed.

\section{Materials and Methods}

\subsection{Laser Texturing}

Surface texturing aims to develop outer layers of reduced thickness with specific microstructural properties, decreasing the heated irradiated area. In this study, the laser texturing of a Ti6Al4V alloy has been carried out using an ytterbium fiber infrared pulsed laser system Rofin EasyMark F20 (ROFIN-SINAR Technologies Inc., Plymouth, MI, USA) with $1070 \pm 5 \mathrm{~nm}$ wavelength, $60 \mu \mathrm{m}$ spot diameter and $100 \mathrm{~ns}$ pulse width (according to the manufacturer). Surface treatments have been developed under ambient air conditions in order to generate the oxidation of the surface alloy. A bidirectional traces layout has been performed without overlapping throughout the titanium samples, resulting in parallel textured lines with approximately $0.12 \mathrm{~mm}$ between neighboring laser traces. With the purpose of obtaining a higher uniformity in the radiation absorption capacity of the alloy's surface, an adaptation process has been realized by grinding the initial surface finish to 1200 grits (particles per square inch). Subsequently, through parameter combinations of pulse energy $\left(E_{\mathrm{t}}\right)$, fluence or energy density of pulse $\left(E_{\mathrm{d}}\right)$ and scanning speed $\left(V_{\mathrm{s}}\right), 24$ different types of specimens were obtained, keeping a constant laser power of $10 \mathrm{~W}$. With these combinations, a sufficiently broad range of treatments are analyzed to study the behavior of the alloy under different radiation stages-see Table 1 below.

Table 1. Laser processing parameters.

\begin{tabular}{|c|c|c|c|c|c|c|c|c|}
\hline Parameter & \multicolumn{3}{|c|}{$f_{1}$} & \multicolumn{3}{|c|}{$f_{2}$} & \multicolumn{2}{|c|}{$f_{3}$} \\
\hline$f(\mathrm{~Hz})$ & \multicolumn{3}{|c|}{20,000} & \multicolumn{3}{|c|}{50,000} & \multicolumn{2}{|c|}{80,000} \\
\hline$E_{\mathrm{t}}(\mathrm{mJ})$ & \multicolumn{3}{|c|}{0.500} & \multicolumn{3}{|c|}{0.200} & \multicolumn{2}{|c|}{0.125} \\
\hline$E_{\mathrm{d}}\left(\mathrm{J} / \mathrm{cm}^{2}\right)$ & \multicolumn{3}{|c|}{17.68} & \multicolumn{3}{|c|}{7.07} & & \\
\hline Parameter & $V_{1}$ & $V_{2}$ & $V_{3}$ & $V_{4}$ & $V_{5}$ & $V_{6}$ & $V_{7}$ & $V_{8}$ \\
\hline$V_{\mathrm{s}}(\mathrm{mm} / \mathrm{s})$ & 10 & 20 & 40 & 80 & 100 & 150 & 200 & 250 \\
\hline
\end{tabular}

\subsection{Evaluation of Laser Textured Specimens}

In order to assess the effects caused by laser texturing on the surface of titanium alloy specimens, several procedures have been developed, including visual and microscopy inspection, microstructural and compositional analysis, measurement of surface finish, depth evaluation of molten material and hardness variation induced by oxidation. 
The main purpose of visual and microscopy inspection is the detection of surface variations through chromatic changes and microstructural modifications. In order to obtain higher contrast and enhance the detection of different phases and grain sizes of the material surface, a metallographic setup and subsequent chemical attack by Kroll's reagent technique on transverse sections of the irradiated surface have been performed. After sampling the metallographic setup, energy dispersive spectrometry (EDS) analysis has been conducted to evaluate the indications of oxides on the substrate material.

In this work, surface finish measurements have been applied to textured surfaces by using a roughness measurement device: model Mahr Perthometer Concept PGK120 (Mahr technology, Göttingen, Germany). With the aim of characterizing the surface integrity from the microgeometrical point of view, linear profile measurements have been carried out along the entire surface, perpendicularly to the displacement of the laser beam, in order to quantify the average roughness parameter, $R_{\mathrm{a}}$.

By optical and scanning electron microscopy (SEM), some features in the shape of the radiation grooves, undetectable at surface level, have been found. To do this, a metallographic setup was required to inspect the internal section in order to obtain a deeper description of the heat-affected area of laser processing. Subsequently, a depth measurement of the carved grooves, quantifying the thickness of the surface layer affected by the process, has also been performed.

Finally, hardness measurements have been carried out on cross sections of laser-treated samples in a near-surface layer of material, where the thermal affected area and higher oxide concentration gradients are located. To perform this measurement, a Shimadzu (RTY) microdurometer (Kyoto, Japan) has been used with a test load of $245.2 \mathrm{mN}$ (HV 0.025) for a time of $10 \mathrm{~s}$. In order to analyze the goodness of measurements, a series of measurements have been made on untreated Ti6Al4V alloy, obtaining less than a $3 \%$ variation from the nominal value of material hardness.

\section{Results and Discussion}

\subsection{Laser Textured Specimens: Chromatic Variability}

During laser texturing, particles located in the outer layers of the Ti6Al4V alloy react with the oxygen present in the atmosphere, causing oxidation of the material surface and forming a thin layer of titanium oxide $\left(\mathrm{Ti}_{y} \mathrm{O}_{x}\right)$. This behavior is mainly caused by the high temperatures produced during laser processing and may also be observed during hard conventional machining processes such as dry drilling in the Ti6Al4V alloy [24]. Regarding this behavior, the oxidation layer is usually composed of various types of oxide, predominantly rutile $\mathrm{TiO}_{2}$ form. Due to the high reactivity between titanium and oxygen particles present in ambient air, a wide range of oxidation states can be developed, being characterized by their color tonality. In this way, through the variation of laser processing parameters (energy density of pulse, scanning speed) associated with the presence of oxidation layers, different treatment intensities may be achieved, obtaining chromatic variation, different thickness and characteristics-see Figure 1.

In the same way as in anodizing processes, the thickness of the modified layer subjected to oxidation is shown as one of the main parameters that affects the chromatic variation of the material [25]. In this aspect, in accordance with Perez del Pino et al. $[15,16]$, it has been detected that, for treatments that involve higher thicknesses of modified layers corresponding to lower $E_{\mathrm{d}}$ and $V_{\mathrm{s}}$, there is a tendency towards bluish and grayish to dark brown color tonalities. On the other hand, by increasing $V_{\mathrm{s}}$ and/or reducing $E_{\mathrm{d}}$, developing modified layers with lower thickness, light brown to golden color tonalities textures are generated. 


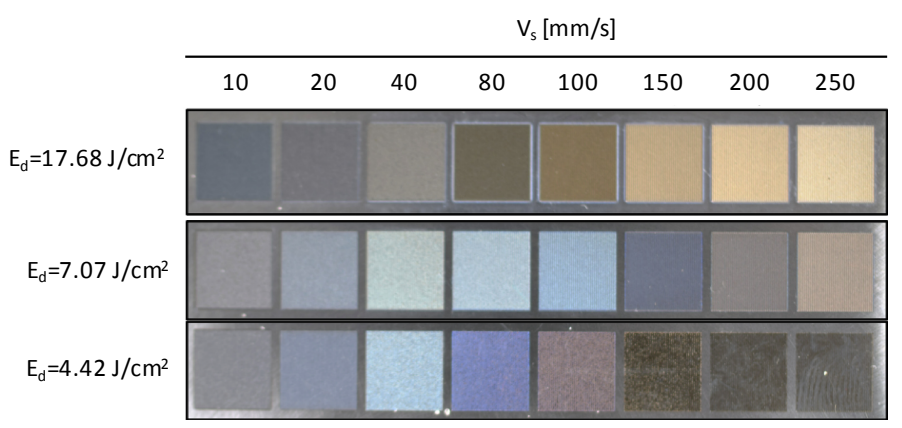

Figure 1. Tonality variations on thermal Ti6Al4V oxidation layers.

\subsection{Laser Textured Specimens: Microstructure and Composition}

The grade 5 titanium alloy (ASTM) used in this study shows an equiaxed or mill-annealed microstructure type, formed by fine grains of $\alpha$ - (lighter) and $\beta$ - (darker) phases. The surface fusion procedure by laser may induce the generation of microstructures which differ from the initial Ti6Al4V alloy, allowing us also to determine the existence of a thermally affected area [26]. It is observed that the zone affected by direct incidence of laser pulses presents variations in the initial composition, surface finish and texture, enabling us to detect alterations in substrate microstructure and oxidation rates of the alloy—see Figure 2.
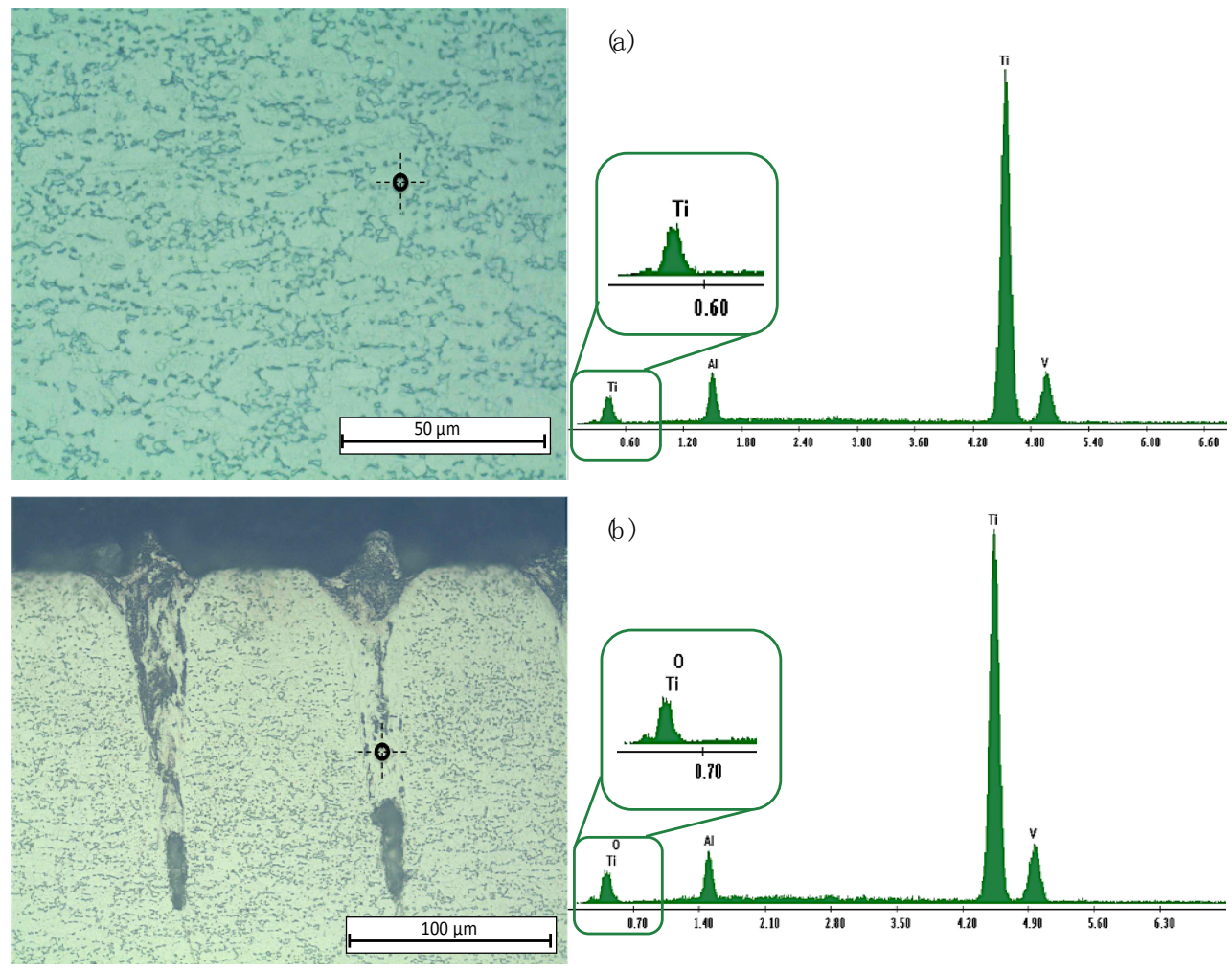

Figure 2. (a) Microstructure and EDS analysis of Ti6Al4V surface; (b) Cross section and EDS analysis of heat affected zone of laser incidence for $17.68 \mathrm{~J} / \mathrm{cm}^{2} ; 10 \mathrm{~mm} / \mathrm{s}$ texturing conditions.

\subsection{Laser Textured Specimens: Surface Finish (Roughness)}

Laser processing parameters have a great influence on the resulting roughness in texturing processes. Therefore, in some cases, a precise control of them may induce the generation of specific microgeometry topographies [17]. 
Starting from polished Ti6Al4V samples with average values of arithmetic average roughness $R_{\mathrm{a}}=0.049 \pm 0.005 \mu \mathrm{m}$ and maximum height of roughness profile $R_{\mathrm{z}}=0.405 \pm 0.070 \mu \mathrm{m}$, the surface finish of the treatments performed indicates that variations in laser texturing parameters have a great influence on the absorption of laser radiation, obtaining a significant variability of roughness values. Moreover, different shapes can be observed in the profiles obtained for different combinations of pulse rate and scanning speed—see Figure 3.

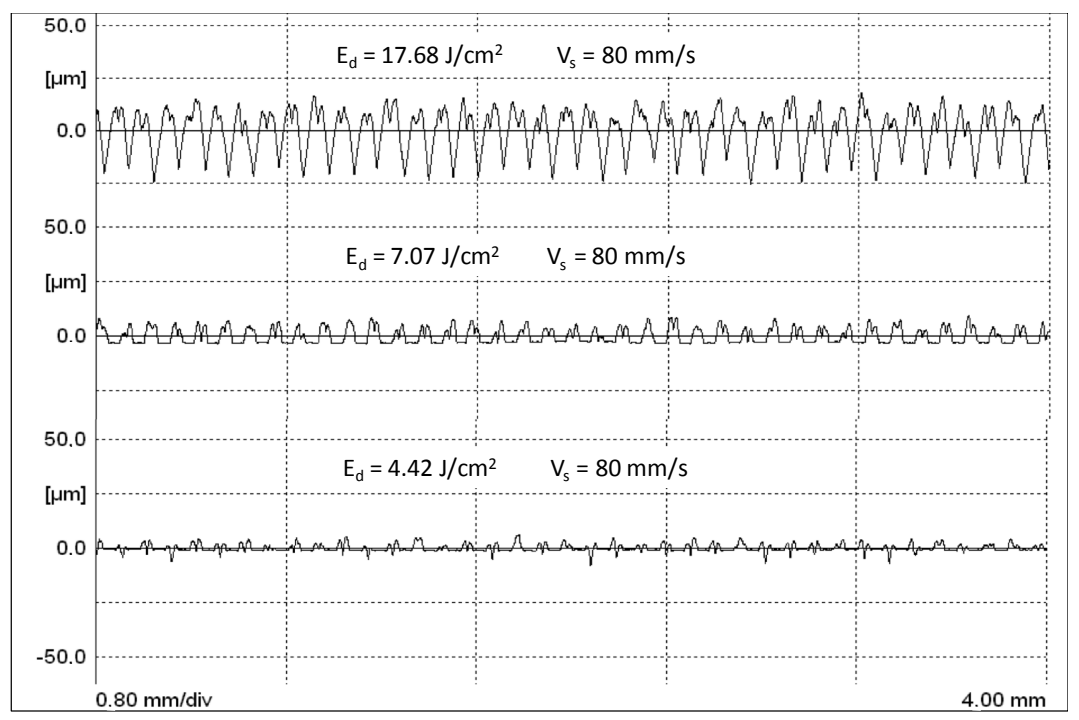

Figure 3. Roughness profiles as a function of energy density of pulse and scan speed of the beam.

Specific combinations of fluence and scan speed result in surface textures with different natures, mainly based on the cooling process and material melted rate. However, it is noteworthy that the energy density of the pulse is shown as the greatest influential parameter on the development of roughness-see Figure $4 \mathrm{a}, \mathrm{b}$. In this aspect, an increase in the pulse rate results in the melting of a higher material thickness, producing a slower solidification process and smoothing the topography of the modified surface. As a consequence of this, more aggressive treatments related to higher energy density absorbed by the surface can result in more volume of melted alloy, increasing the depth and height of the asperities produced by the texturing process.

Analyzing the topography from laser texturing tracks, a wide range of grooves with varying dimensions and geometry may be detected. With the aim of obtaining accurate measurements and an overview of the removed material grooves, a metallographic setup of cross sections of the textured samples has been conducted.

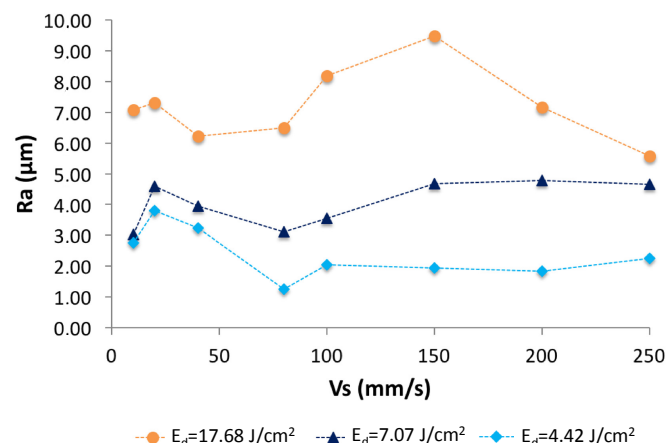

(a)

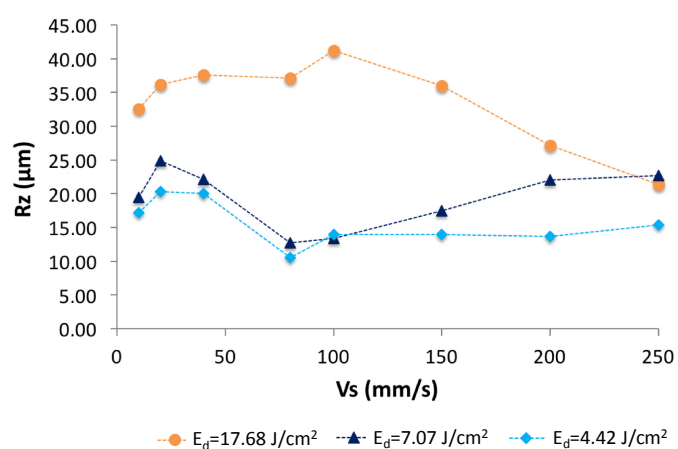

(b)

Figure 4. Surface finish (a) $R_{\mathrm{a}}$ and (b) $R_{\mathrm{z}}$ behavior with different laser processing parameters. 


\subsection{Laser Textured Specimens: Laser Grooves Depth}

In order to obtain accurate information about the surface behavior after the radiation process and to evaluate possible changes in the microstructure of the alloy sections unaffected by thermal oxidation, metallographic preparations of treated samples have been carried out. Thus, through an acid etching procedure, grain boundaries that form the $\alpha$ - and $\beta$-phases of the alloy Ti6Al4V can be clearly revealed.

Due to variations in the frequency and scan speed of the laser parameters, several types of texture and grooves can be observed, influencing the geometry and reaching depth [27], as can be seen in Figure 5. This analysis allows us to perform approaches to the behavior of the material after it has been vaporized by laser irradiation, favoring the evaluation of the heat-affected zone.

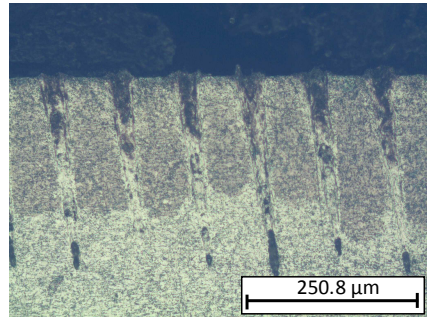

(a)

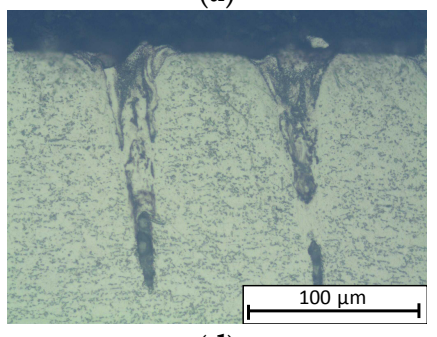

(d)

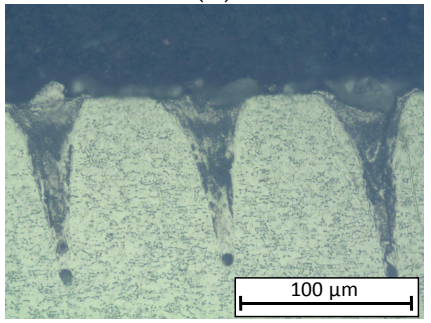

(g)

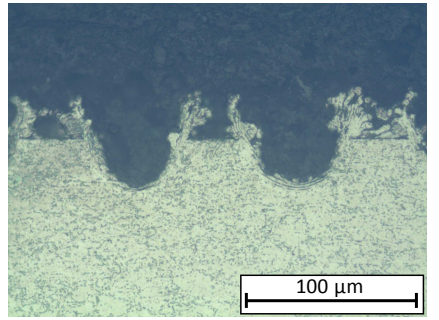

(b)

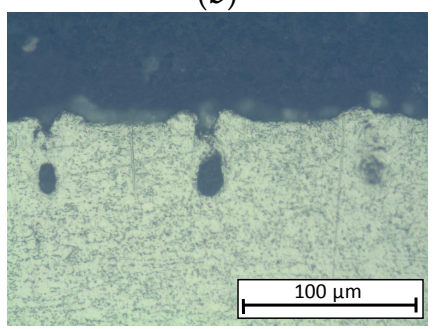

(e)

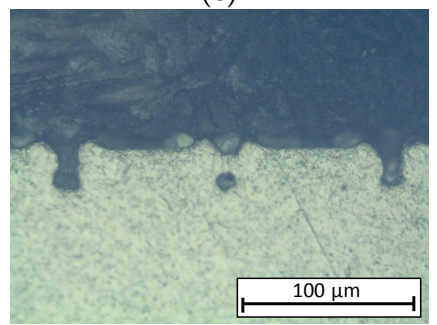

(h)

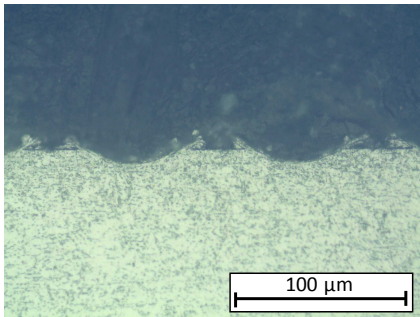

(c)

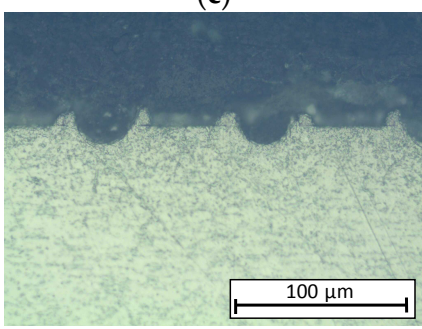

(f)

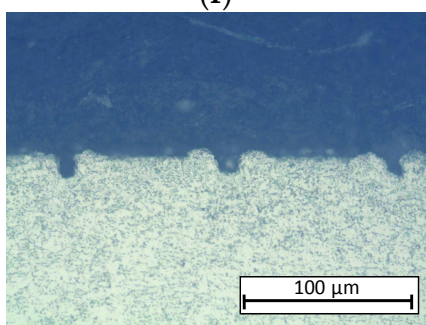

(i)

Figure 5. Different morphology of grooves due to laser absorption features. (a) $17.68 \mathrm{~J} / \mathrm{cm}^{2}, 10 \mathrm{~mm} / \mathrm{s}$; (b) $17.68 \mathrm{~J} / \mathrm{cm}^{2}, 80 \mathrm{~mm} / \mathrm{s}$; (c) $17.68 \mathrm{~J} / \mathrm{cm}^{2}, 250 \mathrm{~mm} / \mathrm{s}$; (d) $7.07 \mathrm{~J} / \mathrm{cm}^{2}, 10 \mathrm{~mm} / \mathrm{s}$; (e) $7.07 \mathrm{~J} / \mathrm{cm}^{2}, 80 \mathrm{~mm} / \mathrm{s}$; (f) $7.07 \mathrm{~J} / \mathrm{cm}^{2}, 250 \mathrm{~mm} / \mathrm{s}$; (g) $4.42 \mathrm{~J} / \mathrm{cm}^{2}, 10 \mathrm{~mm} / \mathrm{s}$; (h) $4.42 \mathrm{~J} / \mathrm{cm}^{2}, 80 \mathrm{~mm} / \mathrm{s}$; (i) $4.42 \mathrm{~J} / \mathrm{cm}^{2}, 250 \mathrm{~mm} / \mathrm{s}$.

The depth of grooves produced by laser beam incidence shows direct relationships with the processing parameters. Laser scan speed is presented as the most influential parameter in the track depth value generated by radiation. However, the increase of pulse energy coincident with lower frequency values bound to a greater beam exposure time on a single point, resulting in a significant increase of thickness in the affected layer of the alloy-see Figure 6.

A maximum depth value of approximately $300 \mu \mathrm{m}$ is observed for the highest values of the fluence and scan speed of the beam parameters, showing similar behaviors for the three values of energy density of pulse studied, only decreasing the depth for the lower values. In this aspect, when the scan speed increases, an absorption of a lower density of pulses takes place on the same section of the surface, tending to decrease the incidence depth of the laser beam, developing softer topographies as expected. 


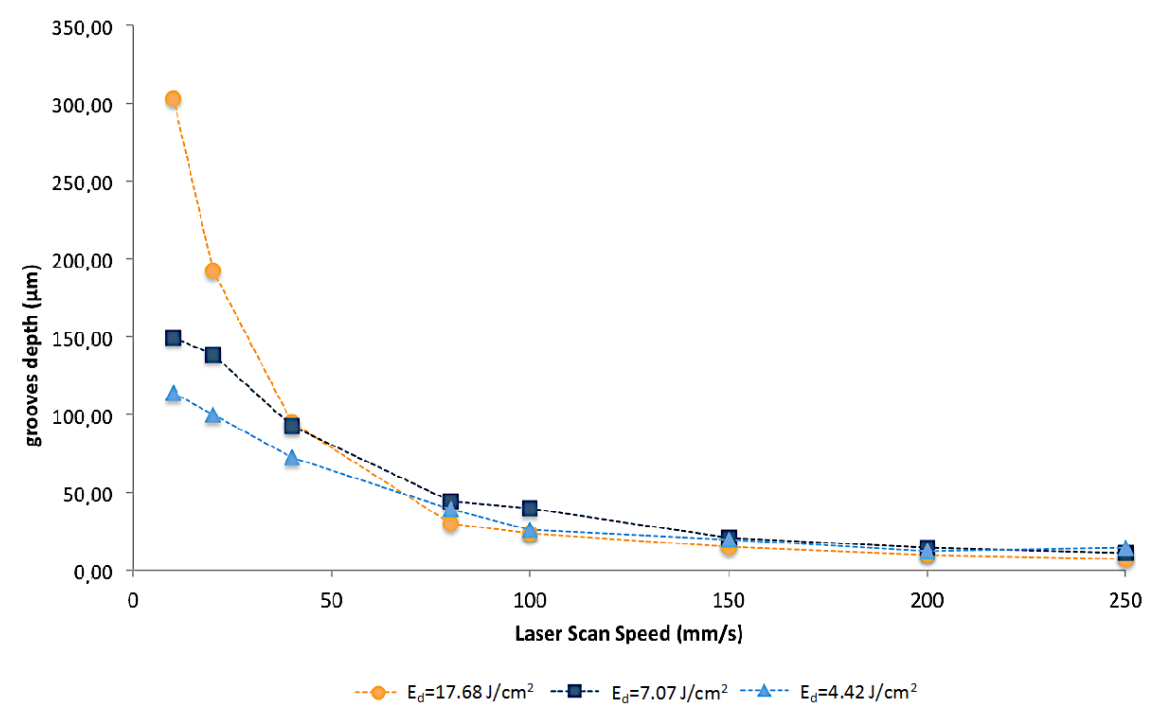

Figure 6. Grooves depth as a function of laser processing parameters.

\subsection{Laser Textured Specimens: Hardness Variation}

Microstructural modification and thermal oxidation of the alloy is usually associated with a hardness variation of the material, as such procedures are used, in most cases, in hardening processes. After hardness measurement located on the cross sections of the texturing grooves, it has been observed that the hardness of the material increases considerably depending on the proximity to the laser irradiated section, obtaining values that can triple the initial value of the base alloy Ti6Al4V—see Figure 7.

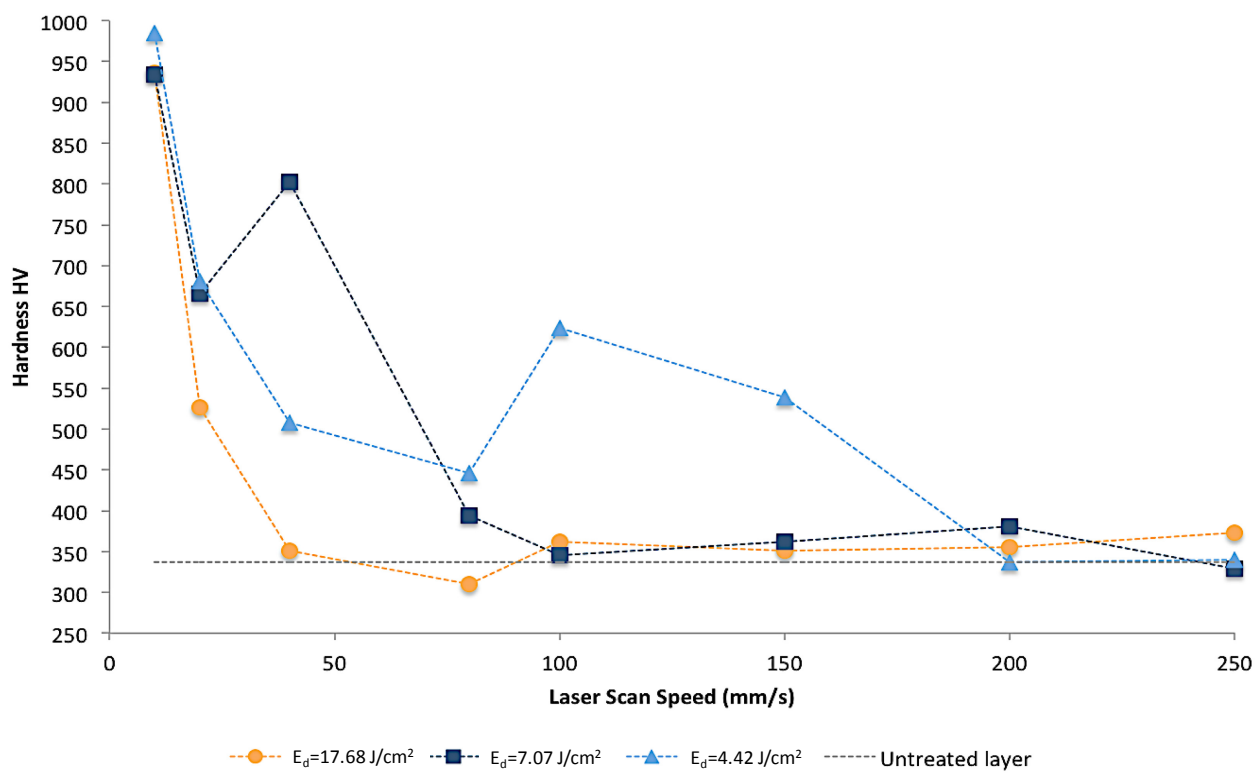

Figure 7. Hardness as a function of laser processing parameters.

As previously indicated, a significant influence of laser parameters can be observed on hardness under thermal oxidation conditions. The proximity to the material surface, and therefore to the remelted layer, results in a hardness increase, expressed with dimensions of Vickers test traces. This fact is due to the existence of microstructural changes of the alloy and oxidation reactions. 
As can be appreciated in Figure 7, there is a clear dependence between hardness values and the scan speed of the laser beam, increasing significantly with lower speeds, which generates samples with higher thicknesses in the irradiated layers.

\section{Conclusions}

Variations of laser processing parameters may induce the formation of modified material layers with different natures and properties. The energy density of the pulse (fluence) $\left(\mathrm{J} / \mathrm{cm}^{2}\right)$ and scanning speed of the beam are the main variables that govern texturing processes.

The different treatments obtained through setup parameter combinations allow the obtaining of samples with widely varying features, according to the thickness of the treated layer and incidence depth of laser beam. This diversity of samples shows a range of color tonalities from soft gold to medium gray and blue.

Laser surface texturing processes greatly affect roughness profiles, with the energy density of pulse $\left(E_{\mathrm{d}}\right)$ being the most relevant parameter in controlling the properties of surface finish. Furthermore, the intensity of treatments, in terms of the incidence absorption of the beam, result in the modification of microstructure and composition (with addition of oxide concentrations) of the outer layers of the alloy. Microstructural changes and oxidation layer generation provide a significant increase in material hardness, reaching Vickers hardness values close to $1000 \mathrm{HV}$ on high intensity treatments.

Acknowledgments: This work has received financial support by the Spanish Government and the Andalusian Government (PAIDI).

Author Contributions: Juan Manuel Vázquez Martínez, Jorge Salguero Gómez and Francisco Javier Botana Pedemonte conceived and designed the experiments; Juan Manuel Vázquez Martínez and Moises Batista Ponce performed the experiments; Juan Manuel Vázquez Martínez, Francisco Javier Botana Pedemonte and Jorge Salguero Gómez analyzed the data; Juan Manuel Vázquez Martínez wrote the paper.

Conflicts of Interest: The authors declare no conflict of interest.

\section{References}

1. Ehtemam-Haghighi, S.; Prashanth, K.G.; Attar, H.; Chaubey, A.K.; Cao, G.H.; Zhang, L.C. Evaluation of mechanical and wear properties of Ti- $x \mathrm{Nb}-7 \mathrm{Fe}$ alloys designed for biomedical applications. Mater. Des. 2016, 111, 592-599. [CrossRef]

2. Okulov, I.V.; Volegov, A.S.; Attar, H.; Bönisch, M.; Ehtemam-Haghighi, S.; Calin, M.; Eckert, J. Composition optimization of low modulus and high-strength TiNb-based alloys for biomedical applications. J. Mech. Behav. Biomed. Mater. 2017, 65, 866-871. [CrossRef] [PubMed]

3. Okulov, I.V.; Wendrock, H.; Volegov, A.S.; Attar, H.; Kühn, U.; Skrotzki, W.; Eckert, J. High strength beta titanium alloys: New design approach. Mater. Sci. Eng. A 2015, 628, 297-302. [CrossRef]

4. Le Guéhennec, L.; Souedidan, A.; Layrolle, P.; Amouriq, Y. Surface treatments of titanium dental implants for rapid osseointegration. Dent. Mater. 2007, 23, 844-854. [CrossRef] [PubMed]

5. Ponsonnet, L.; Reybier, K.; Jaffrezic, N.; Comte, V.; Lagneau, C.; Lissac, M.; Martelet, C. Relationship between surface properties (roughness, wettability) of titanium and titanium alloys and cell behavior. Mater. Sci. Eng. C 2003, 23, 551-560. [CrossRef]

6. Rosales-Leal, J.I.; Rodriguez-Valverde, M.A.; Mazzaglia, G.; Ramon-Torregrosa, P.J.; Diaz-Rodriguez, L.; Garcia-Martinez, O.; Vallecillo-Capilla, M.; Ruiz, C.; Cabrerizo-Vilchez, M.A. Effects of roughness, wettability and morphology of engineered titanium surfaces on osteoblast-like cell adhesion. Colloid Surf. A Physicochem. Eng. Asp. 2010, 365, 222-229. [CrossRef]

7. Le Guehennec, L.; Lopez-Heredia, M.A.; Enkel, B.; Weiss, P.; Amouriq, Y.; Layrolle, P. Osteoblastic cell behavior on different titanium implant surfaces. Acta Biomater. 2008, 4, 535-543. [CrossRef] [PubMed]

8. Feng, B.; Weng, J.; Yang, B.C.; Qu, S.X.; Zhang, X.D. Characterization of surface oxide films on titanium and adhesion of osteoblast. Biomaterials 2003, 24, 4663-4670. [CrossRef]

9. Amaya-Vazquez, M.R.; Sanchez-Amaya, J.M.; Boukha, Z.; Botana, F.J. Microstructure, microhardness and corrosion resistance of remelted $\mathrm{TiG}_{2}$ and $\mathrm{Ti} 6 \mathrm{Al} 4 \mathrm{~V}$ by a high power diode laser. Corros. Sci. 2012, 56, 36-48. [CrossRef] 
10. Lednev, V.N.; Pershin, S.M.; Ionin, A.A.; Kudryashov, S.I.; Makarov, S.V.; Ligachev, A.E.; Rudenko, A.A.; Chmelnitsky, R.A.; Bunkin, A.F. Laser ablation of polished and nanostructured titanium surfaces by nanosecond laser pulses. Spectrochim. Acta Part B 2013, 88, 15-19. [CrossRef]

11. Weng, F.; Chuanzhong, C.; Yu, H. Research status of laser cladding on titanium and its alloys: A review. Mater. Des. 2014, 58, 412-425. [CrossRef]

12. Attar, H.; Ehtemam-Haghighi, S.; Kent, D.; Okulov, I.V.; Wendrock, H.; Bönisch, M.; Volegov, A.S.; Calin, M.; Eckert, J.; Dargusch, M.S. Nanoindentation and wear properties of Ti and Ti-TiB composite materials produced by selective laser melting. Mater. Sci. Eng. A 2017, 688, 20-26. [CrossRef]

13. Attar, H.; Ehtemam-Haghighi, S.; Kent, D.; Wu, X.; Dargusch, M.S. Comparative study of commercially pure titanium produced by laser engineered net shaping, selective laser melting and casting processes. Mater. Sci. Eng. A 2017, 705, 385-393. [CrossRef]

14. Wen, M.; Wen, C.; Hodgson, P.; Li, Y. Thermal oxidation behavior of bulk titanium with nanocrystalline surface layer. Corros. Sci. 2012, 59, 352-359. [CrossRef]

15. Pérez del Pino, A.; Serra, P.; Morenza, J.L. Coloring of titanium by pulsed laser processing in air. Thin Solid Films 2002, 415, 201-205. [CrossRef]

16. Pérez del Pino, A.; Fernandez-Pradas, J.M.; Serra, P.; Morenza, J.L. Coloring of titanium through laser oxidation: Comparative study with anodizing. Surf. Coat. Technol. 2004, 187, 106-112. [CrossRef]

17. Adams, D.P.; Murphy, R.D.; Saiz, D.J.; Hirschfeld, D.A.; Rodriguez, M.A.; Kotula, P.G.; Jared, B.H. Nanosecond pulsed laser irradiation of titanium: Oxide growth and effects on underlying metal. Surf. Coat. Technol. 2014, 248, 38-45. [CrossRef]

18. Vazquez-Martinez, J.M.; Salguero, J.; Botana, F.J.; Contreras, J.P.; Fernandez-Vidal, S.R.; Marcos, M. Metrological evaluation of the tribological behavior of laser surface treated Ti6Al4V alloy. Procedia Eng. 2013, 63, 752-760. [CrossRef]

19. Ukar, E.; Lamikiz, A.; Martinez, S.; Tabernero, I.; López de Lacalle, L.N. Roughness prediction on laser polished surfaces. J. Mater. Process. Technol. 2012, 212, 1305-1313. [CrossRef]

20. Lavisse, L.; Jouvard, J.M.; Imhoff, L.; Heintz, O.; Korntheuer, J.; Langlade, C.; Bourgeois, S.; Marco de Lucas, M.C. Pulsed laser growth and characterization of thin films on titanium substrates. Appl. Surf. Sci. 2007, 253, 8226-8230. [CrossRef]

21. Mahamood, R.M.; Akinlabi, E.T.; Shukla, M.; Pityana, S. Scanning velocity influence on microstructure, microhardness and wear resistance of laser deposited Ti6Al4V/TIC composite. Mater. Des. 2013, 50, 656-666. [CrossRef]

22. Vazquez-Martinez, J.M.; Salguero, J.; Botana, F.J.; Gomez-Parra, A.; Fernandez-Vidal, S.R.; Marcos, M. Tribological wear analysis of laser surface treated Ti6Al4V based on volume lost evaluation. Key Eng. Mater. 2014, 615, 82-87. [CrossRef]

23. Dongqin, H.; Zheng, S.; Pu, J.; Zhang, G.; Hu, L. Improving tribological properties of titanium alloys by combining laser surface texturing and diamond-like carbon film. Tribol. Int. 2015, 82, 20-27.

24. Salguero, J.; Batista, M.; Sanchez, J.A.; Marcos, M. An XPS study of the stratified Built-Up layers developed onto the tool surface in the dry drilling of Ti alloys. Adv. Mater. Res. 2011, 223, 564-572. [CrossRef]

25. Vera, M.L.; Avalos, M.C.; Rosenberger, M.R.; Bolmaro, R.E.; Schvezov, C.E.; Ares, A.E. Evaluation of the influence of texture and microstructure of titanium substrates on $\mathrm{TiO}_{2}$ anodic coatings at $60 \mathrm{~V}$. Mater. Charact. 2017, 131, 348-358. [CrossRef]

26. Vrancken, B.; Thijs, L.; Kruth, J.P.; van Humbeeck, J. Heat treatment of Ti6Al4V produced by selective laser melting: Microstructure and mechanical properties. J. Alloys Compd. 2012, 541, 177-185. [CrossRef]

27. Fasai, A.Y.; Mwenifumbo, S.; Rahbar, N.; Chen, J.; Li, M.; Beye, A.C. Nano-second UV laser processed micro-grooves on Ti6Al4V for biomedical applications. Mater. Sci. Eng. C 2009, 29, 5-13. [CrossRef]

(C) 2017 by the authors. Licensee MDPI, Basel, Switzerland. This article is an open access article distributed under the terms and conditions of the Creative Commons Attribution (CC BY) license (http://creativecommons.org/licenses/by/4.0/). 